\title{
Comment on Reynolds and Limpo
}

\section{L. BEALE and A. S. W. WINTON. Department of Psychology,} University of Auckland, New Zealand

The report by Reynolds \& Limpo (1968) that negative behavioral contrast cannot be regarded as resulting from the alleviation by an increase in reinforcement frequency of the aversive consequences of a previous reduction in reinforcement appears to take cognizance of only one of the aversive effects that might operate in the situation under study. The authors are able to conclude that the negative contrast resulting from increasing the reinforcment rate in the previous $S$ - cannot be clearly caused by the aversive effects generated by the reduction in reinforcement density in $S$ - at the beginning of discrimination training, 92 sessions before. However, the particular explanation criticized by Reynolds and Limpo does not seem a particularly deserving or even popular example of the alternative explanations based on aversive effects.

The most orderly relations between reinforcement and response frequencies in multiple schedules are in terms of relative rather than absolute frequencies (Reynolds, 1963: Lander \& Irwin, 1968). It follows that changes in relative frequencies of reinforcement or responding are the variables most likely to be systematically related to changes in the quality of stimulus control during discrimination. It has been shown that reducing the frequency of reinforcement in one component of a multiple schedule produces inhibitory control (cf., Jenkins, 1965) by the stimulus correlated with that component (Honig et al, 1963), the emotional concomitants of which have been remarked upon by a number of investigators (e.g., Terrace, 1966; Bloomfield, 1966). If these effects are conceived of as arising from a reduction in the relative frequency of reinforcement in $S$-, then it follows that an increase in reinforcement frequency during $S$ - will lead in turn to the development of inhibitory control by $\mathrm{S}+$, since the relative frequency of reinforcement in S+ will be reduced. Experiments in our laboratory have shown that inhibitory control does develop in this situation.

Consequently, both the positive and negative contrast in Reynolds and Limpo's experiment may be explained by appeal to inhibitory processes. It would not be surprising if the inhibitory cause of the second change in behavior (negative contrast) were in the second change in procedure, as this analysis suggests; Reynolds and Limpo only failed to find it in the first change in procedurc.

\section{REFERENCES}

BLOOMFIELD, T. M. Two types of behavioral contrast in discrimination learning. Joumal of the Experimental Analysis of Behavior, 1966, 9, 155-161.

HONIG, W. K., BONEAU, C. A., BURSTEIN, K. R., \& PENNYPACKER, H. $S$. Positive and negative generalization gradients obtained after equivalent training conditions. Journal of Comparative \& Physiological Psychology, $1963,56,111-116$.

JENKINS, H. M. Generalization gradients and the concept of inhibition. In D. Mostofsky (Ed.), Stimulus generalization. Stanford: Stanford University Press, 1965. Pp. 55-61.

LANDER, D. G., \& IRWIN, R. J. Multiple schedules: Effects of the distribution of reinforcements between components on the distribution of responses between components. Journal of the Experimental Analysis of Behavior, 1968 , in press.

REYNOLDS, G. S. Some limitations on behavioral contrast and induction during successive discrimination. Joumal of the Experimental Analysis of Behavior, 1963, 6, 131-139.

REYNOLDS, G. S., \& LIMPO, A. J. Negative contrast after prolonged discrimination maintenance. Psychonomic Science, 1968, 10, 323-324.

TERRACE, H. S. Stimulus Control. In W. K. Honig (Ed.), Operent behavior: areas of research and application. Appleton-Century-Crofts, 1966. Pp. 271-344. 